\title{
Enhancing Access to Energy Services for Sustainable Development in Rural Communities
}

\author{
Surya Gyawali ${ }^{1, *}$, Sushil Bahadur Bajracharya ${ }^{1}$, Sudarshan Raj Tiwari ${ }^{1}$, Hans Norve Skotte ${ }^{2}$ \\ ${ }^{1}$ Department of Architecture and Urban Planning, Pulchowk Campus, Institute of Engineering, Tribhuvan University, \\ Nepal \\ ${ }^{2}$ Department of Architecture and Planning, Norwegian Institute of Science and Technology, Trondheim, Norway \\ Corresponding Email: gyawalisurya@ioe.edu.np
}

\begin{abstract}
:
Access to energy has been based on physical availability, acceptability, adequacy, affordability, reliability, and quality of supply. In addition to physical access, real access to energy services can be limited by the purchasing power of the household, the cost of energy and cost or energy-using equipment. However, ensuring adequate energy for a healthy life implies that the types and amount of energy should meet basic minimum needs without adverse health impacts. The purpose of the paper is to explore the dimensions of energy access to rural communities in developing countries for enhancing sustainable development objectives. The systematic literature review methodology has been used to define approaches of sustainability of energy access and try to understand the linkage between modern energy access to sustainable development for rural communities. The study is stabilized that, redefinition and standard thresholds for sustainable energy services in local community level are crucial for human welfare and health, efficiency and productivity, as well as impacts on the environment, must be linked with sustainable development. Measuring sufficiency or adequacy is harder to define because this may vary from amazingly from region to region depending on climate, customs, and living standards. The study provides a unique insight into the needs, feelings and capabilities of people living with and without modern energy and related innovations and it contributes how these are mobilized and constrained in ways that may extend existing inequalities and the barriers to meaningful access, but also may signify means to overcome them.
\end{abstract}

Keywords: Energy Access, Modern Energy, Sustainable Development, Energy Services, Total Energy Access

\section{Introduction}

Access to energy has gained significant interest from governments and development agencies, particularly since the call for Sustainable Energy for All (SE4ALL) by the Secretary-General of the United Nations in 2012. One of the key goals of SE4ALL is to achieve "universal access to modern energy services by 2030 " [1]. Achieving that goal will require a concerted international effort, substantial new investment, the deployment of new technologies, and a wide range of interventions targeted on underserved populations.

The data and projections presented in World Energy Outlook focus on two elements of energy access: a household having access to electricity and clean cooking facilities. The International Energy Agency defines energy access as "a household having reliable and affordable access to both clean cooking facilities and to electricity, which is enough to supply a basic bundle of energy services initially, and then an increasing level of electricity overtime to reach the regional average". By defining access to modern energy services at the household level, it is recognized that some other categories are excluded, such as electricity access to businesses and public buildings that are crucial to economic and social development, i.e. schools and hospitals [2].

The availability of electricity and clean fuels, however, is highly unequal, resulting in a dependency on unsustainable natural resources limiting social capabilities, resilience, and sustainability for more than 2 billion people in developing countries and less developed countries. Accordingly, access to modern energy services is a foundation for sustainable development and one that has recently become a foremost international and national priority. The burgeoning 'energy access' projects that have emanated from this, however, have met pervasive challenges and limited impacts. There is a need, therefore, for new frameworks for realizing energy-based sustainable development [3]. Hence, the critical role played by energy in achieving sustainable development has been well recognized and the access to energy has been identified as a major challenge. There is also a consensus that without affordable, reliable, and clean 
energy services to the population, the sustainability objective cannot be achieved [4].

For universal energy access to be achieved, about 150 million more people per year must get lifetime access to clean cooking facilities and about 75 million people per year must get access to reliable and adequate electricity by 2030. On current projections for the Poor People's Energy Outlook 2012, drawing together available data, in 2030: 3 billion people will still cook with traditional fuels; almost 900 million people will not have access to electricity; in the next 20 years more than 30 million people will die due to smoke-related diseases; many hundreds of millions will be confined to poverty as their incomes are constrained by lack of energy access.

According to the National Planning Commission (2013), there is conflicting data regarding population-having access to electricity ranging from 53 percent to 74 percent in Nepal. In rural areas, electricity supply from off-grid hydropower plants is limited to an average of above 120 watts per households. Electricity is used mostly for lighting, charging mobile phones, and powering small equipment and appliances. Electricity from solar PV homes systems is even more limited, to an average of about 40 percent of the day on average. Households without electricity access depend on kerosene lamps for lighting. Nepal's electricity consumption per capita 139 $\mathrm{kWh}$ [5] compare to other countries in South Asia is low. About 87 percent of the rural population of Nepal still depend on solid fuel (73 percent fuelwood and 14 percent animal dung) for cooking [6].

The term "energy access" is used to mean access to modern and clean energies by the population of a country. Generally, the term is used to reflect the condition of people in developing countries who rely on traditional energies to satisfy their energy needs. It focuses on whether consumers have physical access to the supply of energy, and access to markets for equipment. Energy access is predominantly a rural problem of poor developing countries [4].

Several approaches have commonly been used by countries to enhance energy access but the emphasis was mostly on electrification, with cooking energy access receiving limited and often sporadic efforts [4]. Providing access to modern energy carriers and end-use conversion devices, such as cleaner cookstoves, is a major step to enable people living in poverty to improve their lives [7].

Energy demand in poor households normally arises from two major end-uses: lighting and cooking (including preparation of hot water). Cooking energy demand is predominant in most cases and often accounts for about $90 \%$ of the energy demand by the poor. Such a high share of cooking energy demand arises partly from its low energy efficiency and partly due to limited scope for other end-uses. As electricity is considered the appropriate form of energy for lighting, it is customary to associate the access to clean lighting to the level of electrification of a country. Access to clean cooking energies, on the other hand can take different paths and therefore the accessrelated information is generally presented for electricity and for cooking energies separately [4].

Without access to energy services, people must spend a great deal of time and physical energy on basic substance activities rather than on earning money. Also, lack of energy correlates closely with many indicators of poverty, such as poor education, inadequate health care, and hardships imposed on women and children [8]. At the local and national levels, reliable energy supply is essential to economic stability and growth, jobs, and improved living standards [9]. The growing demand in developing countries for energy services presents a historic opportunity to satisfy demand in ways that are compatible with sustainable development. If renewable energy, energy efficiency, and clean conventional technologies are more widely used with a focus on decentralized systems, benefits can be reaped for economic, and social development as well as for environmental protection [8].

This paper will provide an overview of key existing approaches to defining energy access and access to modern energy is enhancing rural communities. The paper will conclude with a discussion of what can be learned from the existing work in this area to draw recommendations for a way forward with defining energy access and a proposal for a means to operationalize the definition by constructing a set of metrics that may be used to monitor progress towards a universal energy access goal. In this section has presented the background of the field of research, aspects of the problems, identified the research gaps, and purpose of the study about energy access and sustainable development. The next section reviews the approaches to defining energy access and dimensions including availability, adequacy, affordability, reliability and energy services.

\section{Approaches to defining energy access}

Access is often associated with freedom of choice. Conversely, the lack of access is often associated with deprivation or, in other words, a constraint on people's choices in terms of their inability to access certain goods, 
services, assets, capabilities, freedoms, and opportunities. Access has been defined in the past based on several dimensions such as physical availability, acceptability, adequacy, affordability, reliability, and quality of supply. Beyond these dimensions, there is also interest in assessing the development impacts of using modern energy carriers and technologies for human welfare and health, efficiency and productivity, as well as impacts on the environment [10].

There is no single internationally-accepted and internationally-adopted definition of modern energy access. Yet significant commonality exists across definitions, including:

- Household access to a minimum level of electricity.

- Household access to safer and more sustainable (i.e. minimum harmful effects on health and the environment as possible) cooking and heating fuels are stoves.

- Access to modern energy that enables productive economic activity, e.g. mechanical power for agriculture, textile, and other industries.

- Access to modern energy for public services, e. g. electricity for health facilities, schools and street lighting [11].

The simplest definition of universal access to modern energy is the physical availability of electricity and modern energy carriers and improved end-use devices such as cookstoves at affordable prices for all. A target of energy access for all by 2030, set by the United Nations Secretary-General's Advisory Group on Energy and Climate Change [12], recommends access to be provided in accordance with this basic definition so as to enhance services such as lighting, cooking, heating, and motive power for populations in developing countries.

Sufficiency or adequacy is harder to define because this may vary tremendously from region to region depending on climate, customs, and living standards. However, ensuring adequate energy for a healthy life implies that the types and amounts of energy should meet basic minimum needs without adverse health impacts, where minimum needs might be defined locally and could include both consumptive and productive end-uses. Adequacy can also be defined in terms of security and quality of supplies, that is, for energy to be available regularly, reliably, and be of a standard quality such that supplies are uninterrupted and unadulterated. In the following sections, various existing approaches to defining access are discussed [10].

\subsection{Physical availability of carriers}

Energy access, at an international level, is most often defined in terms of the physical availability of modern energy carriers, including electricity and fuels such as liquefied petroleum gas (LPG), for meeting basic household needs such as lighting and cooking [13]. While physical availability provides a simple metric for capturing one dimension of access, it ignores several other dimensions or attributes associated with access and can leave room for ambiguity as regards the spatial scale at which access is defined (e.g. at a community level or household level). Physical availability includes a geographical dimension. In other words, it deems that supplies should be available in proximity to where a household is located or within a certain community. However, beyond a coverage and supply element, it does not provide any guidelines regarding other specific dimensions such as accessibility, adequacy, affordability acceptability and reliability or indeed even how sustainable the supply may be [10].

\subsection{Adequacy or availability above minimum threshold quality}

Some of the earliest approaches to defining energy access have been in terms of a minimum threshold in terms of a quantity of energy below which access is considered insufficient.

\subsection{Affordability}

In addition to physical access, many have argued that financial access is important. Affordability requires that modern energy be supplied to households at prices that even the poorest can pay. In a broader sense, affordability requires that both capital or upfront costs and operating costs should be commensurate with current income levels. In many countries, the share of expenditures on energy to the average total income or household expenditure is often used as a measure of affordability. The rationale of using such an indicator is that when this ratio falls below a certain threshold, it signifies that energy is affordable and people are not spending excessive amounts on energy or having to reduce their expenditures on other essential commodities. When it exceeds an established threshold, it implies that energy is not affordable and people are having difficulty obtaining enough to meet their needs [10].

\subsection{Quality and reliability}

While there is less literature on defining access solely in terms of quality and reliability, there are clear indications of the high costs associated with not providing regular, reliable and standardized qualities of both energy carriers 
Table 1: Total energy access minimum standards proposed-revised for 2012

\begin{tabular}{|c|c|}
\hline Energy service & Minimum standards \\
\hline \multirow{2}{*}{ Lighting } & 300 lumens for a minimum of 4 hour per night per household \\
\hline & $\begin{array}{l}1 \mathrm{~kg} \text { wood fuel or } 0.3 \mathrm{~kg} \text { charcoal or } 0.04 \mathrm{~kg} \text { LPG or } 0.21 \text { of kerosene or ethanol per person per day, taking less } \\
\text { than } 30 \mathrm{~min} \text { per household per day to obtain }\end{array}$ \\
\hline $\begin{array}{l}\text { Cooking and } \\
\text { water heating }\end{array}$ & $\begin{array}{l}\text { Minimum efficiency of improved solid fuel stoves to be } 40 \text { percent greater than a three-stone fire in terms of fuel } \\
\text { use }\end{array}$ \\
\hline Space heating & $\begin{array}{l}\text { Annual mean concentrations of particulate matter (PM2.5) }<10 \mu \mathrm{g} / \mathrm{m}^{3} \text { in households, with interim goals of } 15 \\
\mu \mathrm{g} / \mathrm{m}^{3}, 25 \mu \mathrm{g} / \mathrm{m}^{3} \text { and } 35 \mu \mathrm{g} / \mathrm{m}^{3}\end{array}$ \\
\hline \multirow[b]{2}{*}{ Cooling } & Minimum daytime indoor air temperature of $12^{\circ} \mathrm{C}$ \\
\hline & $\begin{array}{l}\text { Households can extend the life of perishable products by a minimum of } 50 \text { percent over that allowed by ambient } \\
\text { storage }\end{array}$ \\
\hline \multirow{3}{*}{$\begin{array}{l}\text { Information and } \\
\text { communications }\end{array}$} & Maximum apparent indoor air temperature or $30^{\circ} \mathrm{C}$ \\
\hline & People can communicate electronic information from within their household \\
\hline & People can access electronic media relevant to their lives and livelihoods in their household \\
\hline \multirow{2}{*}{$\begin{array}{l}\text { Earning a } \\
\text { living }\end{array}$} & Access to energy is sufficient for the startup of any enterprise \\
\hline & The proportion of operating costs for energy consumption in energy-efficient enterprises is financially sustainable \\
\hline
\end{tabular}

Source: Poor People's Energy Outlook, 2012

and technologies [14]. Besides, when supplies are irregular, households are more likely to stack fuels in order to maximize security. Defining access in terms of quality and reliability is difficult and little data exist currently to measure this dimension. The World Bank collects some national-level statistics of electric power outages. However, spatially disaggregated information regarding the quality and regularity of supply of other fuels and even electricity are sorely lacking. Also, there is little information available regarding the quality or standards of stoves and other energy-using end-use technologies in use globally. Harmonized and minimum standards for energy technologies, such as stoves or solar home systems, can be important for improving customer confidence and encouraging the adoption of these [10].

\subsection{Minimum energy services to Total Energy Access}

Energy services for basic needs: In rural households, energy is needed to meet basic subsistence needs essential for a minimum level of human comfort. These needs consist of cooking, lighting, space-heating, and the operation of household appliances and devices. Of these, cooking energy needs constitute about $80 \%$ of the household energy needs in rural areas [15]. Rural households use some different forms of energy to minimize both the costs and the risks arising from unstable supply and technologies. For example, in China, it is not unusual to find households with a solar cooker, biogas ring, and both coal and residue-burning stoves.

Recent attempts at defining access have aimed at providing minimum thresholds, not in energy terms but terms of actual service levels. Practical Action (2012) defines six core categories of basic energy services including lighting, cooking and water heating, space heating, cooling, information and communications and earning a living. As a result of a recent web-based econsultation, they have proposed minimum standards, both in qualitative and quantitative terms for each of these basic energy services. Table 1 provides a list of the six core or basic energy services as defined by Practical Action and a set of nine minimum standards proposed by them as needed for ensuring total energy access (TEA) at the household level.

The TEA approach has connected with the viewpoints of others working on this issue: UNIDO et al., (2011) for example states that 'current supply-led approaches that focus on the provision of modern energy carriers are not sufficient for reaping the full potential of social, economic improvements which follow from improved energy access'. The UN Secretary-General's Advisory Group on Climate Change [12] goes beyond this, defining energy access as 'access to clean, reliable, and affordable energy services for cooking and heating, lighting, communications, and productive uses' [16]. Besides, a supply-led regime would just assume that the household could use electricity for heating or make some other plan from the energy source available [17].

Energy planning often takes place far from those without energy access; leaving them unseen, unheard and underrepresented. The community-driven (Demand-led) energy access plans use the UN Sustainable Energy for All (SEforALL) initiative's Multi-Tier Framework to measure existing and required levels of energy access. 
This Total Energy Access (TEA) approach encompasses:

- All spheres of energy access: households, productive uses, and community facilities, differentiated by the gender;

- All forms of energy access: electricity, cooking, heating and mechanical power; and

- All feasible and appropriate means of energy provision: grid-connected, mini-grid, and stand-alone

A demand-led approach would also plan at a much more local scale and try to create closed/no waste systems [17]. This approach used to identify the combination of energy access technologies which provide the best means of economically meeting all of the people's energy access needs on the tight 2030 timeline.

Increasing use of energy services can have both positive and negative effects on the accessibility of employment for poor people in the sectors above. In some cases, it can reduce the need for unskilled labor, often provided by poor people excluded from education and skills training systems. However, in the employment sectors of agriculture, industry, and services - all are seen to be improved in their efficiency or quality through the application of energy services (e.g. improved productivity of agriculture, lighting, ICTs in education, and energy services for increased comfort in hotels and restaurants) [16].

\section{Links between energy and sustainable development}

Although energy is not directly one of the three components of environmental sustainability, economic sustainability, and social sustainability, it is indirectly linked to each [18]. The synergic relation between modern energy access, development, and the environment is well known and considered a central element in the debate [19]. Therefore, accessibility (to modern energy) is an essential theme that needs to be captured in a sustainability assessment. Also, huge inequality in the distribution of the energy resources can be observed among rich and poor even where there is access. This disparity (in electricity and energy use) is mainly due to uneven income distribution that restricts the poor from having a decent life. These two themes are important to cover a social dimension [20].

One of the main obstacles for rural people in getting reliable modern energy access is their affordability [21]. The share of energy expenditure to total disposable income is one way of capturing affordability [22].
Interruptions in energy supply can cause huge financial and economical loses and hinder the market penetration of such energy resources. Therefore, the security of the energy supply is also one important objective and a sustainability criterion to be considered [23]. The share of renewable energy sources in electricity generation provides a measure of the degree of cleanliness and selfreliance in electricity generation. Electricity has multiple uses and is crucial for the socio-economic development of rural households. It is difficult to distinguish the amount of electricity that is used for lighting, other consumptive uses and productive uses such as part of a micro-enterprise conducted within the home [16]. However, the previous study has shown a positive relationship between household electricity use and income for the poor population [24]. A significant positive correlation has been observed between human development and per capita electricity consumption, specifically for countries with low to medium human development [25]. A recent study for developing countries has shown that a 1 percent increase in per capita electricity consumption increases the HDI by 0.22 percent [26]. Therefore, per capita, electricity consumption can be expected to have a positive impact on rural sustainability. All the four aspects aforementioned are crucial to take into account sustainability assessment from an economic dimension [20].

Depending upon geo-climatic conditions, per capita, energy use for cooking /heating may vary. Hence, access to modern fuel and end-use efficiency (i.e. conversion efficiency of stoves) are more relevant indicators from a sustainability perspective rather than capturing the amount of per capita energy use itself [20]. From a technical perspective, maximizing the overall conversion efficiency of fuels used for cooking should be important for the efficient utilization of resources. Also, transmission and distribution (T \&D) loss of electricity are normally quite high in rural areas because of long transmission lines and widespread extensive of lowvoltage distribution networks to extensive areas without proper planning [27]. This causes significant power losses and poor quality of electricity supply. Therefore, capturing the conversion efficiency of stoves and T \& D losses of electricity in the sustainability analysis is important from a technical dimension.

Burning of solid fuels in traditional stoves at poor efficiency poses a significant public health hazard, predominantly affecting rural women and children [22]. The overexploitation of fuelwood may also lead to deforestation in rural areas. The percentage change in 
forest area is another indicator, which can capture an important aspect of rural energy sustainability. Apart from this, the conversion of tropical forests to agricultural land and other uses has caused deforestation. Forests are not only important to provide fuelwood in rural areas, but also important to protect soil and water, to conserve biodiversity and for the provision of other social services [28]. Similarly, greenhouse gas emissions due to the production of electricity from different sources and the burning of different fuels in households have global impacts via climate change. Considering these local and global environmental impacts, it is crucial to conduct a sustainability assessment from an environmental perspective [29] .

Energy services are essential for sustainable development. How these services are produced, distributed, and used effects the social, economic and environmental dimensions of any development achieved. Although energy itself is not a basic human need, it is critical for the fulfillment of all needs [8]. Energy services include things such as lighting, cooking, heating and cooling, water pumping, refrigeration, transportation, and communication. Lack of access to diverse and affordable energy services means that the basic needs of many people are not being met [30].

A lack of access to modern energy services limits economic opportunities and widens the gap between the rich and the poor. Poor people are often cut off from valuable information and efficient production technologies.

\section{Discussion and Recommendations}

The study contributes both methodological and theoretical insights on multi-faced nature of the concept of energy access for enhancing sustainable energy access in rural communities. Several observations can be made.

First, the study is stabilized that, there to the common definition of energy access, many approaches have adopted by governments and development agencies. Expanding energy access is extremely challenging. However, universal energy access is feasible and the barriers that hinder the achievement of this goal can be overcome. In the case of Thailand, the share of the population with access to electricity went from 25 percent to almost 100 percent in just over a decade (from 1980 to the early 1990s) [31].

Second, the results from the study indicate that consensus needs to be established for defining at least energy services need to be established, that is included in a basket of basic energy needs and minimum thresholds level of satisfaction. The levels defined by Practical Action (2012) can be a good starting point for setting these minimum thresholds. However, translating these into energy forms will be done at the national/ local level with a mix of energy carriers at local availability.

Third, to enhance that energy access efforts are sustainable in long run, the cost of the provided energy services should be affordable enough to the lowestincome households is crucial to the success of any efforts and for enhancing equity in energy access.

Four, however, the approach in which energy access is understood has directly impact on planning and implementation of energy system without additional policies aimed at increasing access to energy in developing countries, there will only be little progress towards reducing energy poverty. The IEA (2011), for example, in its New Policies Scenario, estimates that the share of the global population lacking access to electricity will decline from 19 percent in 2009 to 12 percent in 2030.

Five, most importantly, needs to redefine the dimensions of energy access to enhance the sustainability of energy access for rural communities. Hence, definitions and minimum standards of energy service access are crucial to providing modern energy access is ultimately the purpose of enhancing sustainable development objectives.

Last, Nepal has on the process of the post-disaster reconstruction phase. Hence, the lesson learned from this study is highly relevant for preparing effective postdisaster reconstruction policy including sustainability of rural energy access in developing countries like Nepal. Further study is needed to clarify these complexities of sustainable energy access and to test the wider applicability of findings in this study.

\section{References}

[1] UN, Sustainable Energy for All: Technical Report of ask Forse 1, The Secretary-General's High-level Group on Sustainable Enery for All United Nations, 2012.

[2] IEA, World Energy Outlook 2017, Paris: OECD/IEA, 2017.

[3] C. Lewis, Energy 'access' for sustainable development: Enabling modern energy practice in rural communities, London: the University of Sheffield, 2017.

[4] A. Goidthau, "Energy Access and Development," in The Handbook of Global Energy Policy, WILEYBLACKWELL, 2013, pp. 227-243.

[5] IEA, World Energy Outlook 2014, Paris: OECD/IEA, 2014. 
[6] NPC, Sustainable Energy for All. Nepal: Rapid assessment and gap analysis., Kathmandu: National Planning Commission, 2013.

[7] GEA, Global Energy Assessment Toward a Sustainable Future, UK and New York: International Institute of Applied Systems Analysis, Vienna, Austria and Cambridge University press, Cambridge, 2012.

[8] K. Kaygusuz, "Energy for sustainable development: Key issues and challenges," Energy Sources, Part B: Economics, Planning, and Policy, vol. 2, no. 1, pp. 7383, 2007.

[9] H. Gunerham and S. Agi, "Energy-Environment-City Triangle," Energy Sources, vol. 26, no. 7, pp. 697-706, 2004.

[10] S. Pachauri, "Reaching an international cosensus on defining moderg energy access," Current Openion in Environmental Sustainability, vol. 3, pp. 231-240, 2011.

[11] IEA, World Energy Outlook 2017, Paris: OECD/IEA, 2017.

[12] AGECC, "Energy for Sustainable Future: Sunnery Report and Recommendations," The Secretary-General's Advisory Group on Energy and Climate Change, United Nations, New York, 2010.

[13] UNDP and WHO, The Energy Access Situation in developing Countries: A Review Focusing on Least Developed Countries and Sub-saharan Africa, UNDP and WHO, 2009.

[14] E. Kateregga, "The welfare costs of electricity outage: A contingent valuation analysis of households in the suberbs of Kampala, Jinja and Entebbe," Journal of Development and Agricultural Economics, vol. 1, no. 1, pp. 001-011, 2011.

[15] K. Kargusuz, "Energy services and energy poverty for sustainable rural development," Elsevier, vol. 15, no. 2, pp. 936-947, 2011.

[16] IEA, World Energy Outlook 2012, Paris: OECD/IEA, 2012.

[17] UN-Habitat, Sustainable Urban Energy Planning: A handbook for cities and towns in developing countries, ICLEI-Local Government for Sustanabilityy, UN-Habitat and UNEP, 2009.

[18] M. Rosen, Towards energy sustainability: A quest of global promotion, Forum on Public Policy, 2015.

[19] IEA, World Energy Outlook 2011, Paris: OECD/IEA, 2011.

[20] B. Mainali, Sustainability of rural energy access in developing countries, Stockholm: Department of Energy Technology/Energy and Climate Unit, KTH Royal Institute of Technology, 2014.

[21] S. Abdullh and A. Markandya, "Rural electrification programmes in Kenya: Policy conclusion from a valuation study," Energy for Sustainable Development, vol. 16, no. 2012, pp. 103-110, 2012.
[22] IAEA, "Annual report 2005," International Atomic Energy Agency, 2005.

[23] IEA, World Energy Outlook 2005, Paris: OECD/IEA, 2005.

[24] N. Rao, "Does (better) electricity supply increase household enterprise income in India?," Energy Policy, vol. 57, no. 2013, pp. 532-541, 2013.

[25] Pasternak, "Global Energy Futures and Human Development: a Framework for Analysis, U.S. Department of Energy," Lawrence Livermore National library, 2000.

[26] N. S. Ouedraego, "Energy consumption and human development: Evidence from a panel co-integration and error correction model," Energy, vol. 63, pp. 28-41, 2013.

[27] H. I. Rehman, A. Kar, M. Banerjee, P. Kumar, M. Shardul, J. Mohanty and I. Hossain, "Understanding the political economy and key drivers of energy access in addressing national energy access priorities and policies," Energy Polict, vol. 47, pp. 27-37, 2012.

[28] FAO, Global Forest Resources Assessment 2010, Rome: Food and Agiculture Organization of United Nation, 2010.

[29] W. Bank, The Welfare Impact of Rural Electrification: A assessment of costs and benefits, World Bank, 2008.

[30] J. A. Fay and D. S. Golomb, Energy and Environment, Oxford University Press, 2002.

[31] M. Bazian, P. Nussbaumer, H. Rorgner and D. M. Karmmen, Energy Access Scenarios in Sub-Saharan Africa, Vienna: United Nations Industrial Development Organization, 2010.

[32] D. S. Shonali Pachauri, "Energy use and energy accessin relation to poverty," Economic and Political weekly, vol. 39, no. 3, pp. 271-278, 2007.

[33] A. Goldthau, "The Handbook of Global Energy Policy," in Energy Access and Development, WILEYBLACKWELL, 2013, pp. 227-243. 